УДК 616.9:616-07

И.Н.Шарова ${ }^{1}$, Е.С.Казакова ${ }^{1}$, С.А.Портенко ${ }^{1}$, Т.Ю.Красовская ${ }^{1}$, Н.А.Осина ${ }^{1}$, В.Е.Куклев ${ }^{1}$, И.Г.Карнаухов ${ }^{1}$, С.А.Щербакова ${ }^{1}$, А.В.Топорков ${ }^{1}$, М.В.Чеснокова ${ }^{2}$, А.Н.Куличенко ${ }^{3}$, В.В.Кутырев ${ }^{1}$ СОВЕРШЕНСТВОВАНИЕ И СТАНДАРТИЗАЦИЯ ЛАБОРАТОРНОЙ ДИАГНОСТИКИ
ОСОБО ОПАСНЫХ, «НОВЫХ И ЩВОЗВРАЩАЮЩИХСЯ» ИНФЕКЦИОННЫХ БОЛЕЗНЕЙ

${ }^{1}$ ФКУЗ «Российский научно-исследовательский противочумный институт «Микроб», Саратов, Российская Федераиия; ${ }^{2}$ ФУЗ "Иркутский научно-исследовательский противочумный институт Сибири и Дальнего Востока», Иркутск, Российская Федерация; ${ }^{3}$ ФКУЗ «Ставропольский научно-исследовательский противочумный институт», Ставрополь, Российская Федераџия

Представлены основные этапы стандартизации лабораторной диагностики особо опасных инфекционных болезней и совершенствования нормативно-методической базы по порядку организации и проведения лабораторной диагностики в соответствии с трехуровневой структурой.

Определены принципы, схема индикации и идентификации ПБА новых, ранее не известных, атипичных микроорганизмов, основанных на использовании современных автоматизированных систем и высокотехнологичного оборудования.

Ключевые слова: стандартизация лабораторной диагностики, особо опасные инфекции, индикация и идентификация «новых» и «возвращающихся» инфекционных болезней.

I.N.Sharova ${ }^{1}$, E.S.Kazakova1, S.A.Portenko ${ }^{1}$, T.Yu.Krasovskaya ${ }^{1}$, N.A.Osina ${ }^{1}$, V.E.Kuklev ${ }^{1}$, I.G.Karnaukhov ${ }^{1}$, S.A.Shcherbakova ${ }^{1}$, A.V.Toporkov ${ }^{1}$, M.V.Chesnokova ${ }^{2}$, A.N.Kulichenko ${ }^{3}$, V.V.Kutyrev ${ }^{1}$

\title{
Improvement and Standardization of Laboratory Diagnostics Procedures as Concerns Particularly Dangerous, “Emerging", and "Reemerging" Infectious Diseases
}

${ }^{1}$ Russian Research Anti-Plague Institute "Microbe”, Saratov, Russian Federation; ${ }^{2}$ Irkutsk Research Anti-Plague Institute of Siberia and Far East, Irkutsk, Russian Federation; ${ }^{3}$ Stavropol Research Anti-Plague Institute, Stavropol, Russian Federation

Represented are the data on the key stages of laboratory diagnostics practices standardization as regards particularly dangerous infectious diseases and on the improvement of the normative-regulatory framework on the procedure for organization and carrying out laboratory diagnostics in accordance with three-level system. Worked out are the principles, scheme of indication and identification of pathogenic biological agents of emerging, previously unknown, and atypical microorganisms using modern computerized systems and high-tech equipment.

Key words: standardization of laboratory diagnostics practices, particularly dangerous infections, indication and identification of "emerging", and "reemerging" infectious diseases.

Ситуация по инфекционным болезням на протяжении последних десятилетий характеризуется устойчивой тенденцией появления новых (неизвестных) и возвращения известных инфекционных болезней. Лабораторную диагностику особо опасных, «новых» и «возвращающихся» инфекционных болезней в ходе эпидемиологического надзора и санитарной охраны территории Российской Федерации осуществляют учреждения Федеральной службы по надзору в сфере защиты прав потребителя и благополучия человека (Роспотребнадзор), включая мобильные лабораторные комплексы специализированных противоэпидемических бригад (СПЭБ), и ряд других ведомств в рамках функционирования Единой национальной системы индикации и идентификации возбудителей опасных инфекционных болезней.

Функции и задачи учреждений, входящих в эту систему, регламентированы приказом Роспотребнадзора № 88 от 17.03.2008 г. «О мерах по совершенствованию мониторинга за возбудителями инфекционных и паразитарных болезней», определившим концепцию трехуровневой структуры ла- бораторной диагностики инфекционных болезней на территориальном, региональном и федеральном уровнях. Основанная на принципах территориальной организации, взаимосвязи и взаимодействия различных учреждений, дифференциальном подходе к номенклатуре исследований, а также единстве требований биологической безопасности [1] трехуровневая структура стала одним из этапов стандартизации лабораторной диагностики опасных инфекционных болезней в Российской Федерации.

Дальнейшиеэтапысовершенствования истандартизации лабораторной диагностики инфекционных болезней направлены на организацию и проведение диагностических исследований с учетом требований международных стандартов, внедрение современных автоматизированных и информационных технологий, обеспечивающих получение достоверных и надежных результатов, нормативное закрепление изменений в методических документах. В результате реализации ряда НИОКР в ходе выполнения федеральной целевой программы «Национальная система химической и биологической безопасности Российской 
Федерации» была усовершенствована нормативнометодическая база лабораторной диагностики особо опасных инфекционных болезней в соответствии с трехуровневой структурой. Разработаны методические указания по порядку организации и проведения лабораторной диагностики чумы, холеры, сибирской язвы, туляремии, бруцеллеза, лихорадки Западного Нила, Крымской геморрагической лихорадки, сапа и мелиоидоза, которые регламентируют номенклатуру и объем исследований в соответствии с уровнем организации лабораторной базы, подготовку специалистов, материально-техническое оснащение лабораторий с учетом требований международного стандарта ГОСТ-Р ИСО-МЭК 17025 «Общие требования к компетентности испытательных и калибровочных лабораторий», определяют порядок взаимодействия учреждений Роспотребнадзора. С целью стандартизации диагностических исследований, выполняемых в лабораториях СПЭБ, разработан базовый комплект стандартных операционных процедур (СОП) для каждого этапа лабораторной диагностики опасных инфекционных болезней.

Одной из приоритетных задач лабораторной службы в рамках санитарной охраны территории Российской Федерации остается выявление и идентификация возбудителей новых, ранее не известных инфекционных болезней. Решение этой задачи возложено на лаборатории Центров индикации и диагностики возбудителей опасных инфекционных болезней и возможно только при использовании современных лабораторных и информационных технологий. Это, в свою очередь, требует совершенствования нормативно-методического обеспечения проводимых работ.

Основным направлением совершенствования лабораторной диагностики при идентификации как возбудителей известных инфекционных болезней бактериальной и вирусной природы, так и новых или атипичных ПБА, является использование автоматизированных систем на всех этапах диагностических исследований и внедрение в лабораторную практику современных подходов на основе морфометрического, масс-спектрометрического, молекулярногенетических и других видов анализа $[10,12]$. Так, использование масс-спектрометрии позволяет идентифицировать микроорганизмы на основании уникальных для каждого вида ПБА масс-спектров, характеризующих структуру и молекулярный вес биомолекул (рибосомальные и другие белки, пептиды, олигонуклеотиды) [4-6]. Применение технологии мультисубстратного тестирования, основанной на принципах турбидиметрической и/или колориметрической детекции, позволяет идентифицировать чистые культуры микроорганизмов за 4-8 ч, без проведения дополнительных и уточняющих тестов $[2,3]$. Для определения чувствительности микроорганизмов к антибактериальным препаратам (АБП) применяют аналитические системы, основанные как на рутинных подходах (диско-диффузионный метод
(ДДМ) и метод серийных разведений), так и на основе метода масс-спектрометрии, что позволяет быстро выявить наиболее эффективные в отношении изучаемого возбудителя препараты $[8,11]$. Автоматическая обработка полученных данных дает возможность рассчитать минимальные ингибирующие концентрации препаратов и подобрать оптимальные терапевтические дозы, а также обнаружить формирование устойчивости микроорганизмов к АБП, в том числе и при использовании ДДМ [11]. Метод фрагментарного секвенирования позволяет с помощью технологий капиллярного электрофореза или пиросеквенирования определять нуклеотидные последовательности участков генома микроорганизмов: $16 \mathrm{~S}$ рДНК или других генов жизнеобеспечения для возбудителей бактериальной природы, D2 сегмента гена большой субъединицы рибосом - для микозов, консервативных участков генома - для вирусов [7]. Риботипирование - метод идентификации микроорганизмов на основании количества и расположения в геноме патогена rrn оперонов. Для проведения анализа может быть использована автоматизированная система РибоПринтер и база данных рибопринтеров, специфичных для широкого круга микроорганизмов [9]. Морфометрический анализ - измерение геометрических размеров клеток микроорганизмов с помощью метода атомно-силовой микроскопии дает возможность идентифицировать ПБА на основании различий в морфологии и поверхности клеток и наличию субклеточных структур.

В настоящее время разработка алгоритма выявления и идентификации ПБА с использованием комплекса высокотехнологичных методов анализа является приоритетным направлением дальнейшего совершенствования и стандартизации лабораторной диагностики особо опасных инфекций в целом.

Основными принципами специфической индикации и лабораторной диагностики особо опасных, «новых» и «возвращающихся» инфекционных болезней являются: использование единой комплексной схемы анализа; использование единого комплекса методов исследования, в том числе высокотехнологичных; применение единого подхода молекулярного типирования патогенов; использование для учета и обработки данных биоинформационных систем; использование единой схемы передачи информации о результатах исследований.

Единая схема специфической индикации и идентификации ПБА должна включать:

- на преаналитическом этапе стандартные процедуры отбора, приема, регистрации, первичной обработки и подготовки проб к исследованию;

- на аналитическом - выявление в исследуемом материале маркеров (антигенов, антител, ДНК/РНК) возбудителей вирусной и бактериальной природы, а также токсинов с использованием комплекса методов; биологическое обогащение проб (посев на среды накопления, культуры клеток, заражение РКЭ и биопробных животных) с последующей детекцией 
возбудителей методами МФА, ИФА, ПЦР; выделение культуры возбудителя; идентификацию выделенных микроорганизмов как с помощью методов, регламентированных действующими нормативнометодическими документами, так и с использованием расширенного спектра методов, позволяющих определять таксономическую принадлежность, эпидемическую значимость, вирулентность, генетический и белковый профиль возбудителя; молекулярнобиологическое типирование возбудителей с применением амплификационных (ПЦР, RAPD, MLVA), рестрикционных (RFLP, AFLP, PFGE, риботипирование), секвенационных (SNP, SNR, MLST, CRISP, полногеномное секвенирование), а также постгеномных (протеомный и биоинформационный анализ) технологий;

- на постаналитическом - анализ и оценку результатов исследования с использованием компьютерных информационно-аналитических программ.

Таким образом, совершенствование и стандартизация лабораторной диагностики путем внедрения автоматизированных систем на всех этапах диагностических исследований, оснащения лабораторий современным аналитическим оборудованием, лабораторными информационными системами, широким спектром диагностических средств, а также внедрение нормативно-методических документов, регламентирующих порядок организации и проведения лабораторной диагностики в соответствии с трехуровневой системой, учитывающих требования международных стандартов, обеспечит надежность и качество диагностических исследований, повысит производительность и эффективность лабораторий, осуществляющих диагностику особо опасных, «новых» и «возвращающихся» инфекционных болезней.

\section{СПИСОК ЛИТЕРАТУРЫ}

1. Онищенко Г.Г., Кутырев В.В., редакторы. Лабораторная диагностика опасных инфекционных болезней. Практическое руководство. М.: Медицина, Шико; 2009. 472 с.

2. Bochner B.R. Global phenotypic characterization of bacteria. FEMS Microbiol. Rev. 2009; 33(1): 91-205.

3. Crowley E., Bird P., Fisher K., Goetz K., Boyle M., Benzinger M.J. Jr., Juenger M., Agin J., Goins D., Johnson R. Evaluation of the VITEK 2 Gram-negative (GN) microbial identification test card: collaborative study. J. AOAC Int. 2012; 95(3):778-85.

4. Drevinek M., Dresler J., Klimentova J., Pisa L., Hubalek $M$. Evaluation of sample preparation methods for MALDI-TOF MS identification of highly dangerous bacteria. Lett. Appl. Microbiol. 2012; 55(1):40-6.

5. Farfoura E., Leto J., Barritaulta M., Barberis C., Mever J., Dauphin B., Le Guern A.-S., Lefluche A., Badell E., Guiso N., Leclercq A., Le Monnier A., Lecuit M., Rodriguez-Nava V., Bergeron E., Raymond J., Vimont S., Bille E., Carbonnelle E., Guet-Revillet H., Lücuyer H., Beretti J.-L., Vay C., Berche P., Ferroni A., Nassif X. Join-Lambert $O$. Evaluation of the Andromas Matrix-Assisted Laser Desorption Ionization-Time of Flight Mass Spectrometry System for Identification of Aerobically Growing Gram-Positive Bacilli. J. Clin. Microbiol. 2012; 50(8):2702-7.

6. Ferreira L., Castan S.V., Sanchez-Juanes F., GonzalezCabrero S., Menegotto F., Orduna-Domingo A., Gonzalez-Buitrago J.M., Munoz-Bellido J.L. Identification of Brucella by MALDI-TOF mass spectrometry. Fast and reliable identification from agar plates and blood cultures. PLoS One. 2010; 5:14235

7. Grif K., Dierich M.P., Much P., Hofer E., Allerberger F. Identifying and subtyping species of dangerous pathogens by automated ribotyping. Diagn. Microbiol. Infect. Dis. 2003; 47:13-20.

8. Grundt A., Findeisen P., Miethke T., Jäger E., Ahmad-
Nejad P., Neumaier M. Rapid Detection of ampicillin resistance in Escherichia coli by quantitative mass spectrometry. J. Clin. Microbiol. 2012; 50(5):1727-9.

9. Janda J.M., Abbott S.L. 16S rRNA gene sequencing for bacterial identification in the diagnostic laboratory: pluses, perils, and pitfalls. J. Clin. Microbiol. 2007; 49(9):2761-4.

10. Köser C.U., Ellington M.J., Cartwright E.J.P., Gillespie S.H., Brown N.M., Farrington M., Holden M.T.G., Dougan G., Bentley S.D., Parkhill J., Peacock S.J. Routine Use of Microbial Whole Genome Sequencing in Diagnostic and Public Health Microbiology. PLoS Pathog. 2012; 8(8):e1002824.

11. Winstanley T.T., Courvalin P. Expert Systems in Clinical Microbiology. Clin. Microbiol. Rev. 2011; 24(3):515-56.

12. Wolk D.M., Dunne W.M. Jr. New Technologies in Clinical Microbiology. J. Clin. Microbiol. 2011; 49(9):62-7.

\section{References}

1. Onishchenko G.G., Kutyrev V.V., editors. [Laboratory Diagnostics of Particularly Dangerous Infectious Diseases. Practice Guidelines]. M. Meditsina, Shiko; 2009. $472 \mathrm{p}$

2. Bochner B.R. Global phenotypic characterization of bacteria. FEMS Microbiol. Rev. 2009; 33(1): 91-205.

3. Crowley E., Bird P., Fisher K., Goetz K., Boyle M., Benzinger M.J. Jr., Juenger M., Agin J., Goins D., Johnson R. Evaluation of the VITEK 2 Gram-negative (GN) microbial identification test card: collaborative study. J. AOAC Int 2012; $95(3): 778-85$.

4. Drevinek M., Dresler J., Klimentova J., Pisa L., Hubalek M. Evaluation of sample preparation methods for MALD̈I-TOF MS identification of highly dangerous bacteria. Lett. Appl. Microbiol. 2012; 55(1):40-6.

5. Farfoura E., Leto J., Barritaulta M., Barberis C., Meyer J., Dauphin B., Le Guern A.-S., Lefluche A., Badell E., Guiso N., Leclercq A., Le Monnier A., Lecuit M., Rodriguez-Nava V., Bergeron E., Raymond J., Vimont S., Bille E., Carbonnelle E., Guet-Revillet H., Lücuver H., Beretti J.-L., Vay C., Berche P., Ferroni A., Nassif X., Join-Lambert O. Evaluation of the Andromas MatrixAssisted Laser Desorption Ionization-Time of Flight Mass Spectrometry System for Identification of Aerobically Growing Gram-Positive Bacilli. J. System for Identification of Aerobical
Clin. Microbiol. 2012; 50(8):2702-7.

6. Ferreira L., Castan S.V., Sanchez-Juanes F., Gonzalez-Cabrero S., Menegotto F., Orduna-Domingo A., Gonzalez-Buitrago J.M., Munoz-Bellido J.L. Identification of Brucella by MALDI-TOF mass spectrometry. Fast and reliable identification from agar plates and blood cultures. PLoS One. 2010; 5:14235

7. Grif K., Dierich M.P., Much P., Hofer E., Allerberger F. Identifying and subtyping species of dangerous pathogens by automated ribotyping. Diagn. Microbiol. Infect. Dis. 2003; 47:13-20.

8. Grundt A., Findeisen P., Miethke T., Jäger E., Ahmad-Nejad P., Neumaier M. Rapid Detection of ampicillin resistance in Escherichia coli by quantitative mass spectrometry. J. Clin. Microbiol. 2012; 50(5):1727-9.

9. Janda J.M., Abbott S.L. $16 \mathrm{~S}$ rRNA gene sequencing for bacterial identification in the diagnostic laboratory: pluses, perils, and pitfalls. J. Clin. Microbiol. 2007; 49(9):2761-4.

10. Köser C.U., Ellington M.J., Cartwright E.J.P., Gillespie S.H. Brown N.M., Farrington M., Holden M.T.G., Dougan G., Bentley S.D. Parkhill J., Peacock S.J. Routine Use of Microbial Whole Genome Sequencing in Diagnostic and Public Health Microbiology. PLoS Pathog. 2012; 8(8):e1002824.

11. Winstanley T.T., Courvalin P. Expert Systems in Clinical Microbiology. Clin. Microbiol. Rev. 2011; 24(3):515-56.

12. Wolk D.M., Dunne W.M. Jr. New Technologies in Clinical Microbiology. J. Clin. Microbiol. 2011; 49(9):62-7.

Authors:

Sharova I.N., Kazakova E.S., Portenko S.A., Krasovskaya T.Yu., Osina N.A., Kuklev V.E., Karnaukhov I.G., Shcherbakova S.A., Toporkov A.V., Kutyrev V.V. Russian Research Anti-Plague Institute "Microbe". 46, Universitetskaya St., Saratov, 410005, Russian Federation. E-mail: rusrapi@ microbe.ru

Chesnokova M.V. Irkutsk Research Anti-Plague Institute of Siberia and Far East. 78, Trilissera St., Irkutsk, 664047, Russian Federation. E-mail: adm@chumin.irkutsk.ru

Kulichenko A.N. Stavropol Research Anti-Plague Institute. 13-15, Sovetskaya St., Stavropol, 355035, Russian Federation. E-mail: snipchi@ mail.stv.ru

\section{Об авторах:}

Шарова И.Н., Казакова Е.С., Портенко С.А., Красовская Т.Ю., Осина Н.А., Куклев В.Е., Карнаухов И.Г., Щербакова С.А., Топорков A.B., Кутырев B.B. Российский научно-исследовательский противочумный институт «Микроб». Российская Федерация, 410005, Саратов, ул. Университетская, 46. E-mail: rusrapi@microbe.ru

Чеснокова M.B. Иркутский научно-исследовательский противочумный институт Сибири и Дальнего Востока. Российская Федерация, 664047, Иркутск, ул. Трилиссера, 78. E-mail: adm@chumin.irkutsk.ru

Куличенко А.Н. Ставропольский научно-исследовательский противочумный институт. Российская Федерация, 355035, Ставрополь, ул. Советская, 13-15. E-mail: snipchi@mail.stv.ru 